\title{
Letters
}

Website: www.bmj.com

Email: letters@bmj.com

\section{Antepartum risk factors for newborn encephalopathy}

\section{Intrapartum risk factors are important in developing world}

EDITOR-Badawi et al's case-control study of neonatal encephalopathy in Western Australia shows that clinical evidence of dysfunction of the central nervous system in newborn infants is associated with a wide range of disorders. ${ }^{1}$ For most of their study population these disorders had origins before the onset of labour. We have two concerns about generalising their findings to other populations: their definition of neonatal encephalopathy, and the greater importance of intrapartum risk factors for neonatal encephalopathy in poorer populations in the developing world.

The omission of intrapartum criteria from the case definition of neonatal encephalopathy has been advocated previously and removes an important bias affecting other studies. ${ }^{2}$ The investigators' broad clinical definition of neonatal encephalopathy, however, makes comparison with prevalence studies in other settings problematic. For instance, isolated neonatal seizures are difficult to ascertain clinically. ${ }^{3}$ What proportion of the 109 infants reported to have seizures had interictal evi-

\section{Advice to authors \\ We prefer to receive all responses electronically, sent either directly to our website or to the editorial office as email or on a disk. Processing your letter will be delayed unless it arrives in an electronic form. \\ We are now posting all direct submissions to our website within 72 hours of receipt and our intention is to post all other electronic submissions there as well. All responses will be eligible for publication in the paper journal. \\ Responses should be under 400 words and relate to articles published in the preceding month. They should include $\leqslant 5$ references, in the Vancouver style, including one to the BMJ article to which they relate. We welcome illustrations. \\ Please supply each author's current appointment and full address, and a phone or fax number or email address for the corresponding author. We ask authors to declare any competing interest. Please send a stamped addressed envelope if you would like to know whether your letter has been accepted or rejected. \\ Letters will be edited and may be shortened. \\ www.bmj.com \\ letters@bmj.com} evidence of these. Children, Bristol BS2 8BJ

M.Ellis@bristol.ac.uk child health 1993;35:1022-4. 1989;64:452-8 section requires some clarification. dence of neurological dysfunction? Other investigators have chosen to exclude established causes of encephalopathy such as overt congenital infection and hypoglycaemia from prevalence studies, so it would be helpful for comparative purposes to know what proportion of the authors' cases had

Finally, the inclusion of 37 infants with birth defects (23\% of the cases) clearly has implications for the subsequent analysis of the likely time of the insult. In a high income setting with almost universal antenatal care and a relatively low stillbirth rate, the live birth of neurologically impaired fetuses will probably be maximised. In many low income countries mothers are stunted, do not access antenatal care, have high stillbirth rates, and receive poor obstetric care. Under these conditions intrapartum factors probably remain more important in the causation of neonatal encephalopathy.

Matthew Ellis Lecturer in child health

Institute of Child Health, Royal Hospital for

Anthony M de L Costello Reader in international

Centre for International Child Health, Institute of Child Health, London WC1N 1EH

1 Badawi N, Kurinczuk JJ, Keogh JM, Alessandri LM, O'Sullivan F, Burton PR, et al. Antepartum risk factors for newborn encephalopathy: the Western Australian casecontrol study. BMJ 1998;317:1549-53. (5 December.)

2 Birth asphyxia: a statement. Develop Med Child Neurol

3 Connel J, Oozer R, DeVries L, Dubowitz LMS, Dubowitz V. Continuous EEG monitoring of neonatal seizures: diagnostic and prognostic considerations. Arch Dis Child

Inverse association of risk may be due to easier delivery with elective caesarean

EdiTor-Badawi et al highlight the complex interaction between antenatal and intrapartum risk factors in the aetiology of newborn encephalopathy among term infants. ${ }^{12}$ They have suggested that elective caesarean section is a protective factor; this

Proportions of cases (babies with neonatal encephalopathy) and controls having complicated ${ }^{*}$ and uncomplicated deliveries in Badawi et al's study

\begin{tabular}{lccc} 
& No $(\mathbf{\%})$ of cases $(\mathbf{n}=\mathbf{1 6 4 )}$ & No (\%) of controls $(\mathbf{n}=\mathbf{4 0 0 )}$ & Unadjusted odds ratio (95\% Cl) \\
\hline Complicated delivery & $79(48)$ & $101(25)$ & $2.75(1.88$ to 4.02$)$ \\
\hline Uncomplicated delivery & $85(52)$ & $299(75)$ & $0.36(0.25$ to 0.53$)$ \\
\hline
\end{tabular}

${ }^{\star}$ Complicated deliveries: instrumental deliveries, emergency caesarean sections, breech manoeuvres.

tUncomplicated deliveries: spontaneous vaginal deliveries, induced vaginal deliveries, elective caesarean sections. 


\section{Authors' reply}

EDITOR-Ellis and Costello raise two crucial issues. Firstly, they point out that the risk factor profile and the relative importance of individual risk factors in developing nations may differ from those in the developed world. This is important, because the global burden of perinatal morbidity and mortality falls mainly on the developing nations.

Secondly, they emphasise the need for a standard definition of newborn encephalopathy that does not assume an intrapartum aetiology and explicitly states exclusion criteria. Such criteria may include some birth defects, but this requires debate. In our study, all infants meeting entry criteria were included. This maximises generalisability. Only 11 case infants had birth defects sufficient, on their own, to explain the encephalopathy. Exclusion of these infants made no material difference to our conclusions. Of the 109 case infants with seizures, 104 had evidence of interictal neurological dysfunction.

Murphy raises the role of elective caesarean section. As she points out, when uncomplicated deliveries are compared with complicated deliveries, uncomplicated deliveries are associated with a lower risk (crude odds ratio $0.36(95 \%$ confidence interval 0.25 to 0.53$)$ ). We would not choose this as a primary analysis because the complexity of delivery is in part an outcome of the causal sequence leading to the newborn encephalopathy and should not therefore be treated as a simple explanatory variable. Nevertheless, the stated association clearly exists. But, crucially, it strengthens our belief about the appropriate way to interpret our findings.

We believe four points to be true.

(1) There is a strong negative association between uncomplicated delivery and newborn encephalopathy.

(2) There is a strong negative association between elective caesarean section and newborn encephalopathy.

(3) If analysis is restricted to women who (when conventional criteria are used) might be expected to benefit from an elective section, a strong negative association between elective section and newborn encephalopathy remains.

(4) A relatively large proportion of case mothers who might have been expected to benefit from an elective section did not receive one.

These observations may be interpreted in two ways. Firstly, our study is observational, and the causal pathways leading to newborn encephalopathy are complex. Consequently, our findings may reasonably be interpreted as showing no more than an interesting association. This conclusion would reflect the fact that we have provided absolutely no definitive evidence of a (negative) causal link between elective section and newborn encephalopathy. Conversely, although the study is observational and the causal pathways are complex, it may be argued that one simple hypothesis that would be entirely consistent with the observed associations is that an elective section can, in some at risk pregnancies, mitigate the risk of newborn encephalopathy.

In conclusion, our study does not prove that an elective section protects against newborn encephalopathy. Nevertheless, our data are consistent with such a protective effect. Furthermore, it is difficult to come up with an alternative explanation that is as coherent. In this situation we believe that one must take a decision-theoretical approach to inference by considering the costs and benefits of accepting one interpretation over the other. The former interpretation implies that nothing needs to be done. The latter suggests that further research needs to be undertaken, with study designs that will allow more to be said about the role of elective section in the aetiology of newborn encephalopathy. Given that elective section may genuinely be protective, we believe that to assume the former interpretation is unacceptable.

Nadia Badawi Consultant neonatologis

Jennifer J Kurinczuk Epidemiologist

Fiona J Stanley Director

TVW Telethon Institute for Child Health Research, PO Box 855, West Perth, Western Australia 6872 . Australia

John M Keogh Consultant obstetrician and gynaecologist

Department of Obstetrics and Gynaecology, Hornsby Ku-ring-Gai Hospital, Hornsby New South Wales 2077, Australia

Paul R Burton Senior biostatistician

Department of Paediatrics, University of Western Australia, Western Australia 6907, Australia

\section{Backdoor euthanasia}

Withholding food and fluids is justifiable only for terminally ill

EDITOR-Recent articles in the general ${ }^{1}$ and medical press $^{2}$ on "backdoor euthanasia" illustrate the confusion that surrounds the subject. This is especially true for decisions to withdraw or withhold food and fluids from ill patients. Focusing on the issue of the intention behind such actions may help to achieve some clarity.

Current research, although limited, suggests that the desire for food and drink lessens in terminally ill patients and that artificial hydration neither prolongs survival nor alleviates symptoms. ${ }^{34}$ Furthermore, drips and nasogastric feeding tubes can cause unnecessary distress to patients and their relatives. In such cases the withholding of these treatments is entirely appropriate as the intention is to save the patient from a treatment that has no medical benefit.

But what about those who are not in the terminal stages of an illness-for example, patients who have had a recent stroke or with acute infection? In most instances death is not imminent. However, not providing food and fluids would certainly lead to death. In this case the intention behind the omission is to let the patient die. It fulfils the definition of an act of euthanasia and as such is morally unjustifiable.

This leaves one further question: when is a patient's condition terminal? That is, when is a patient at a stage where recovery is highly improbable and provision of artificial nutrition and hydration is of no benefit? This is not always easy to answer. Clinical signs and biochemical tests act as a good indicator, as does experience in dealing with such cases. But when there is doubt, as there often is, it seems common sense to err on the side of caution and provide all reasonable means to aid recovery, including the basic human needs for food and drink.

James Paul Specialist registrar in palliative medicine Kilburn, London NW6 7HH

JamesPaul@compuserve.com

1 Various articles on euthanasia Times 6 January 1999:1, 2, 9,17 .

Dyer C. Police investigate "euthanasia" deaths. BMJ 1999;318:143. (16 January.)

3 Ellershaw JE, Sutcliffe JM, Saunders CM. Dehydration and the dying patient. J Pain Symptom Management 1995; 10:192-7.

4 Dunlop RJ, Ellershaw JE, Baines MJ, Saunders CM. On withholding nutrition and hydration in the terminally ill: has palliative care gone too far? A reply. J Med Ethics 1995;21:141-3.

\section{Intravenous and enteral fluids may cause} rather than alleviate suffering

EDITOR-I am worried by the recent reporting and police investigation of "euthanasia" deaths due to dehydration. ${ }^{1}$ I was distressed by articles in the Times which seemed to exploit bereaved families who had supported the decline and death of their relatives over many years, by suggesting that they may have suffered unnecessary pain and distress because of poor, or even criminal, mismanagement.

Not all doctors and nurses agree that giving intravenous or enteral fluids to dying patients who can no longer swallow or feel thirst eases suffering. Many experts in palliative care believe the contrary. Zerwekh, a clinical coordinator of the Hospice of Seattle, observed that giving fluids and interfering with the natural course of dehydration can cause acute discomfort to the patient near death and emotional distress to the family.' He commented that if the kidneys have not shut down, the fluids can sharply increase the flow of urine. If patients are extremely weak, have lost bladder control, or are in a coma, this increase may necessitate insertion of a catheter. The fluids also significantly increase gastrointestinal fluids, which is a major problem for patients whose vomiting is difficult to control, especially when there is bowel obstruction requiring a nasogastric tube. Intravenous fluids also tend to increase respiratory secretions, making it more difficult for patients to catch their breath or cough, and suction may be required. Fluids can also cause a flare up of oedema and ascites and expand the oedema layer around tumours, aggravating symptoms, particularly pain.

With increasing reliance on technology rather than nursing and family support for dying patients, we seem to be following North American medicine into the hole that it is currently trying to climb out of. A study of long term patients found that tube feeding did not prevent aspiration pneumonia. The authors concluded "for almost 
all conscious patients we suggest a dedicated attempt at feeding by hand." ${ }^{4}$ As the nurses at Kingsway Hospital observed, ${ }^{2}$ over zealous nil by mouth orders can also cause unnecessary dehydration and suffering. We need to remember the real meaning of the word euthanasia-a quiet and easy death. This is what we all want for ourselves and need to strive to achieve for patients by individual assessment of their needs, not by adherence to prescriptive protocols.

Mary Bliss Consultant geriatrician

Bryning Day Hospital, Homerton Hospital,

London E9 6SR

1 Dyer C. Police investigate "euthanasia" deaths. BMJ 1999;318:143. (16 January.)

2 Various articles on euthanasia Times 6 January 1999:1, 2 9,17 .

3 Zerwekh JV. The dehydration question. Nursing 1983;13: 47-51

4 Finetune TE, Bynum JPW. Use of tube feeding to prevent aspiration pneumonia. Lancet 1996;348:1421-4

\section{Widening screening to detect Chlamydia trachomatis is more important than using DNA methods}

EDITOR-The letter from Taylor-Robinson and Robinson on the use of DNA amplification methods for diagnosing chlamydial infections raises several difficult issues. ${ }^{1}$ The cost of changing to such methods is substantial: we estimate that an additional $£ 5 \mathrm{~m}$ a year would be required for the current workload in genitourinary medicine. In addition, the substantial costs of training, additional space, and gaining formal accreditation would have to be met before the methods could be widely applied. Many laboratories are finding it hard to accept the high costs of amplification tests, even in affluent California.

Any expenditure of this magnitude must be based on the best evidence. A recent French multicentre survey of 28 commercial kits for the diagnosis of chlamydial infection found that enzyme linked immunoassay detection limits varied over a 10-fold range; only two kits attained the same values as direct immunofluorescence assays. ${ }^{3}$ A previous study in Bristol also found variation in performance. ${ }^{4}$ Clearly, the most sensitive enzyme linked immunoassays must be used in trials to establish the true difference in sensitivities. In some reports the difference in sensitivity observed has been much less than that quoted by the authors when the most sensitive enzyme linked immunoassays are used. A recent example is the paper by Tanaka et al on detection in vaginal and cervical swabs; in both cases the best enzyme linked immunoassay gave sensitivities close to those of the polymerase chain reaction. ${ }^{5}$

We are saddened by the suggestion that women who have had a diagnosis by enzyme linked immunoassay might pursue litigation; given all the imponderables of chlamydial infection, we are not convinced that they would be successful. No current test has $100 \%$ sensitivity. Would a woman who had a diagnosis by nucleic acid amplification assay be in a position to sue if the laboratory had not checked her specimen for inhibitors?

We understand the authors' desire to offer patients the best test but are concerned that the high costs of amplification assays will lead to restrictions on testing. This would be disastrous when we could be widening chlamydial screening to reach the substantial number of infected women who currently receive no service at all.

Alan Herring Head, PHLS Genitourinary Infections Reference Laborator

A.Herring@PHLSBRISTOL.btinternet.com

Owen Caul Consultant virologist

Ian Paul Medical laboratory scientific officer

Bristol Public Health Laboratory, Bristol BS2 8EL

Patrick Horner Consultant physician

Milne Centre, Bristol Royal Infirmary, Bristol BS2 8HW

1 Taylor-Robinson D, Robinson AJ. DNA methods should be used to detect Chlamydia trachomatis. BMJ 1998;317 1525. (28 November.)

2 Dean D, Ferrero D, McCarthy M. Comparison of perform ance and cost-effectiveness of direct fluorescent-antibody, ligase chain reaction, and PCR assays for verification of chlamydial enzyme immunoassay results for population with a low to moderate prevalence of Chlamydia trachomatis infection. J Clin Microbiol 1998;36:94-9.

3 Biachi A, De Barbeyrac B, Bebear C, Buffet-Janvresse C, Eb F, Janot C, et al. Multi-laboratory comparison of 28 commercially available Chlamydia trachomatis diagnostic tests. In: Stephens RS, Byrne GI, Chrisiansen G Clarke IN, Crayson JT, Rank RG, et al, Chlarke IN, ial infection. Proceedings of the ninth international symposium on human diamydial infection. San Francisco: Internationa Paul ID, Caul EO. Evaluation of three Chlamydi rachomatis immunoassays with an unbiased, non-invasive clinical sample.J Clin Microbiol 1990;28:220-2.

5 Tanaka M, Nakayama H, Yoshida H, Takahashi K, Nagafuj T, Hagiwara T, et al. Detection of Chlamydia trachomatis in vaginal specimens from female commercial sex worker using a new improved immunoassay. Sex Transm Infed 1998;74:435-8.

\section{Audit of implantable cardioverter-defibrillators in a single UK centre}

EdiTor-We support Causer and Connolly's editorial emphasising the value of implantable cardioverter-defibrillators in patients with life threatening ventricular arrhythmias. ${ }^{1}$ A recent audit conducted in our cardiac unit highlights two additional issues: psychosocial concerns of patients and cost implications. We reviewed clinical records and psychosocial structured questionnaires of the 42 patients receiving their first implantable cardioverter-defibrillator (through pectoral routes) between January 1995 and February 1998 (table). To our knowledge, this is the first reported series of such patients in the United Kingdom.

At audit five patients had died (three from progressive heart failure, two from cancer), three of them within six months of implantation. Twenty five patients received appropriate treatment and thereby survived an otherwise potentially fatal arrhythmia.

Sixteen patients $(38 \%)$ reported some degree of anxiety or depression after implantation of the cardioverter-defibrillator, a percentage similar to that in a larger series of such patients in the United States. ${ }^{2}$ Most of these patients had received multiple shocks from the device. Twenty six patients were unable to drive, and only 12 were in full time
Summary of audit in patients receiving implantable cardioverter-defibrillators. Values are numbers of patients unless stated otherwise

\begin{tabular}{lcc} 
& $\begin{array}{c}\text { Device } \\
\text { activated } \\
(\mathbf{n = 2 5 )}\end{array}$ & $\begin{array}{c}\text { Device not } \\
\text { activated } \\
\mathbf{( n = 1 7 )}\end{array}$ \\
\hline Men, women & 21,4 & 12,5 \\
\hline Age (years): & $31-79$ & $32-74$ \\
\hline Range & $62(11)$ & $53(13)$ \\
\hline Mean (SD) & & \\
\hline Aetiology: & 21 & 12 \\
\hline Ischaemic heart disease & 0 & 1 \\
\hline Coronary artery spasm & 1 & 4 \\
\hline Hypertrophic cardiomyopathy & 3 & 0 \\
\hline Right ventricular dysplasia & & \\
\hline Rhythm: & 7 & 5 \\
\hline Ventricular tachycardia & 18 & 12 \\
\hline Ventricular defibrillation & & \\
\hline Ejection fraction (\%): & $15-70$ & $20-80$ \\
\hline Range & 37 & 46 \\
\hline Mean & 2 & 0 \\
\hline Local complications: & 3 & 3 \\
\hline Related to the lead & 0 & 1 \\
\hline Haematoma & \\
\hline Pneumothorax & & \\
\hline No shoks delvered & & \\
\hline
\end{tabular}

No of shocks delivered during follow up (antitachycardia pacing, ${ }^{*}$ defibrillation):

\begin{tabular}{lcl}
\hline 1 & 6,5 & 0 \\
\hline $2-5$ & 6,5 & 0 \\
\hline $6-9$ & 2,2 & 0 \\
\hline$>10$ & 5,4 & 0 \\
\hline Shocks delivered & 6 & 0
\end{tabular}

inappropriately

\begin{tabular}{lll}
\hline Regular amiodarone treatment & 19 & 12 \\
\hline Readmitted for heart failure or & 10
\end{tabular}

Readmitted for heart failure or

multiple shocks

Quality of life score (maximum 10):

\begin{tabular}{lcc}
\hline Before implantation & 5.6 & 7.2 \\
\hline After implantation & 8.3 & 8.4 \\
\hline Able to drive & 4 & 12 \\
\hline Able to work & 5 & 7 \\
\hline Anxiety present & 8 & 3 \\
\hline $\begin{array}{l}\text { Depression present } \\
\begin{array}{l}\text { Regular antidepressant } \\
\text { treatment }\end{array}\end{array}$ & 4 & 1 \\
\hline
\end{tabular}

treatment

*For ventricular tachycardia.

tDuring sinus rhythm or supraventricular tachycardia.

employment. Overall, however, most patients reported a positive attitude to health and had an improved quality of life score after implantation

The total cost of implantation in the 42 patients was about $£ 850000$ (not including the costs of hospital readmission and follow up care). In comparison with procedures such as renal dialysis or coronary artery bypass surgery, implantation of cardioverterdefibrillators is comparatively cost effective when used in selected high risk groups. However, to base practice in the United Kingdom on evidence from recent trials ${ }^{4}$ would require at least a threefold increase in implantation rate (to about 1000 patients/ year), with a projected total cost to the NHS of $£ 24.1 \mathrm{~m} /$ year.

Patients surviving a first cardiac arrest related to sustained ventricular tachycardia or ventricular fibrillation are at high risk of a further, potentially fatal, event. ${ }^{1}$ An implantable cardioverter-defibrillator can be life 
saving in such people. Psychosocial factors, before and after implantation, need careful evaluation (and appropriate further management) and are as important as the cardiological and cost aspects of treating the malignant arrhythmias. We hope that the results of a study based in the United Kingdom may provide further insight and finally help to identify the subgroup of patients most likely to benefit from having an implantable cardioverter-defibrillator.

Sandeep Gupta Specialist registrar

Hasan Hasan Senior house officer

Oswaldo Valencia Research fellow

Sue Jones Senior pacing coordinator

Edward Rowland Consultant cardiologist

A John Camm Professor of cardiology

Charles W Pumphrey Consultant cardiologist

David E Ward Consultant cardiologist

Department of Cardiology, St George's Hospital,

London SW17 OQT

1 Causer JP, Connolly DT. Implantable defibrillators for life threatening arrhythmias. BMJ 1998;317:762-3. (19 September)

2 Heller SS, Ormont MA, Lidagoster L, Sciacca RR, Steinberg JS. Psychosocial outcome after ICD implantaion: a current perspective. PACE 1998;21:1207-15.

3 Kupperman M, Luce BR, McGovern B, Podrid PJ, Bigger JT, Ruskin JN. An analysis of the cost-effectiveness of the implantable-defibrillator. Circulation 1990;81:91-100.

4 Antiarrhythmics Versus Implantable Defibrillators (AVID) Investigators. A comparison of antiarrhythmic drug therpy with implantable defibrillators in patients resuscitated from near fatal ventricular arrhythmias. N Engl J Med 1997 337:1576-83

5 Pathmanathan RK, Lau EW, Cooper J, Newton L, Skehan JD, Garratt CJ, Griffith MJ. Potential impact of antiarrhythmic drugs versus implantable defibrillators on the me managens of ventands . guided intervention and cardioverter implant registry

\section{Vitamin D concentrations in Asian children living in England}

Limited vitamin $D$ intake and use of sunscreens may lead to rickets

EDITOR-I would like to add a sixth suggestion to Wharton's five approaches to improving children's vitamin D status to prevent rickets. ${ }^{1}$ A case of rickets was recently diagnosed in a 12 month old white infant at the Hospital for Sick Children in Toronto. He had clinical, radiological, and biochemical evidence of rickets, which responded to vitamin D treatment. Vitamin $\mathrm{D}$ intake seemed adequate until six months after treatment began but was sporadic after that. Although the infant spent time outdoors in the summer, his skin was protected with potent sunscreens (SPF 30).

Rickets presumably developed because of limited vitamin D intake combined with diminished skin penetration of ultraviolet radiation. I believe that this is the first case to be diagnosed in a white infant. Although numerous previous reports have documented vitamin $\mathrm{D}$ deficiency rickets from inadequate oral intake of vitamin $\mathrm{D}$, in most cases the infants had dark skin and had limited exposure to ultraviolet B.

The ultraviolet $B$ rays that synthesise vita$\min \mathrm{D}_{3}$ in the skin from 7-dehydrocholesterol are also associated with adverse effects on the skin. Public health advice has emphasised that skin should be shielded from the sun from birth onwards, especially in light skinned individuals. Both Health Canada and the Canadian Dermatology Association advise that infants under 1 year should be kept out of direct sunlight. Infants over 6 months are advised to wear a sunscreen of SPF 15 or higher on all areas that are exposed to the sun. ${ }^{3}$

With the increasing use of sunscreen one may justifiably ask whether infants and children are at an increased risk of vitamin D deficiency. This question is biologically plausible since sunscreens block the absorption of ultraviolet $\mathrm{B}$ radiation. A sunscreen with an SPF of 30, like the one used in this case, allows only a thirtieth of the ultraviolet rays to penetrate the skin. The photoisomerisation of 7-dehydrocholesterol to previtamin $\mathrm{D}_{3}$ is prevented by sunscreens. ${ }^{4}$

Although regular use of sunscreens has been associated with low body stores of vita$\min \mathrm{D},{ }^{5}$ the case presented is the first to document an association between use of sunscreens and vitamin D deficiency rickets Infants who ingest a suboptimal amount of vitamin $\mathrm{D}$ and whose skin is protected by potent sunscreens should receive a vitamin D supplement.

\section{Stanley Zlotkin Professor}

Department of Paediatrics and of Nutritional Sciences, Hospital for Sick Children, Faculty of Medicine, University of Toronto, 555 University Avenue, Toronto, Ontario, Canada M5G 1X8 szlotkin@sickkids.on.ca

Competing interests: Stanley Zlotkin occasionally gives opinions, for which he receives a fee, to companies making nutritional products for children.

1 Wharton BA. Low plasma vitamin D in Asian toddlers in Britain. BMJ 1999;318:2-3. (2 January.)

Mughal MZ, Salama H, Greenaway T, Laing I, Mawer EB. Florid rickets associated with prolonged breast feedin without vitamin D supplementation. BMJ 1999:318:39-40. (2 January.)

3 Health and Welfare Canada. The sun your baby and you: Parent's guide to sum protection. Ottawa: Canadi Gover a ment Publishing Centre Supply and Services, 1996.

4 Matsuoka LY, Ide L, Wortsman J, MacLaughlin JA, Holick

MF. Sunscreens suppress cutaneous vitamin D3 synthesis.J Clin Endocrinol Metab 1987;64:1165-8.

5 Matsuoka LY, Wortsman J, Hanifan N, Holick MF. Chronic sunscreen use decreases circulating concentrations of 25(OH)D. Arch Dermatol 1988;124:1802-4.

\section{Concentrations found may be function of} analytical methodology used

Editor-Lawson and Thomas suggest that the serum concentration of 25hydroxycholecalciferol is substantially lower in Asian infants than in the general population. ${ }^{1}$ Although this finding is highly plausible, their paper does not provide reliable evidence regarding the presence or magnitude of this difference. Plasma samples in Asian subjects were collected in a different year and in a different geographical area and were apparently assayed in a different laboratory from those in the external control group. Analytical methods are unspecified.

Year to year differences in plasma 25-hydroxycholecalciferol are likely. More importantly, the North West Thames external quality assurance survey showed that serum measurements of 25-hydroxycholecalciferol differed considerably both between and within laboratories over the period of the study. ${ }^{23}$ The number of subjects classified as having 25-hydroxycholecalciferol below 25 $\mu \mathrm{mol} / \mathrm{l}$ may be as much a function of analytical methodology as of ethnic group. A similar explanation may account for the apparent absence of seasonal variation in the control data.

Aubrey Blumsohn Senior registrar in biochemical medicine

Directorate of Biochemical Medicine, Ninewells Hospital, Dundee DD1 9SY

ablumsohn@btinternet.com

Competing interests: None declared.

1 Lawson M, Thomas M. Vitamin D concentrations in Asian children aged 2 years living in England: population survey. BMJ 1999;318:28. (2 January)

2 Carter GD, Hewitt J. The 25-hydroxyvitamin D EQAS: an update. Proc UK NEQAS Meeting 1996;2:157. (ISSN 13574558.)

3 Veith R. Vitamin D supplementation, 25-hydroxyvitamin D concentrations, and safety. Am J Clin Nutr 1999;69:

\section{Income distribution, socioeconomic status, and self rated health in US}

\section{Authors ignored data in their study}

EDITOR-I take issue with Kennedy et al's conclusion that the frequently observed association between income inequality and health is not an artefact of an omitted relation between individual income and individual health. ${ }^{1}$ They had only limited information on individual incomes in their study. Furthermore, they ignored some of the income and inequality data that they did have available. Consequently, their conclusion that income inequality exerts an independent effect on individual health is inappropriate.

The authors controlled for individual income by using survey data on household income and controlling for household size. Their income data were categorical and so were necessarily measured with error. The top category was for households with incomes of $\geqslant \$ 50000$ ( $17.3 \%$ of the sample). Without explanation the authors combined this category with the category of households with an income of $\$ 35000$ to $<\$ 50000$ (another $15 \%$ of the sample). The authors also retained observations on people for whom income data were missing ( $12.6 \%$ of the sample). Thus $44.9 \%$ of their sample had missing data or the highest incomes in the study.

The authors also analysed subsamples of their data stratified by income. However, they combined several income categories in each subsample and failed to control for this. Finally, they ignored additional information by using only a four category measure of income inequality even though they had available a continuous measure of it (the Gini coefficient)

Despite these measurement issues, the authors show that the relative risk associated with residence in a state with high income inequality falls by about one third when controls for individual income are added to the logistic regression. This suggests that if 
the authors had more complete data on individual incomes the association between inequality and health might be further mitigated; the apparent association might even disappear completely, which is the opposite of what the authors conclude from their analysis.

By choosing to ignore relevant information Kennedy et al have added to the ambiguity in their findings and unnecessarily undermined the value of their analysis.

Jeffrey Milyo Postdoctoral fellow

Health Policy Program, Yale University, New Haven, CT 06511, USA

jmilyo@tufts.edu

1 Kennedy BP, Kawachi I, Glass R, Prothrow-Stith D. Income distribution, socioeconomic status, and self-rated health in the United States: multilevel analysis. BMJ 1998;317:91721. (3 October)

\section{Authors' reply}

EDITOR-Milyo's main criticism is that we did not adequately address the statistical artefact issue as our estimates of the effects of individual income on health used household income categories rather than a continuous measure of household income. Our study was limited to the income data available to us. Measurement of household income in a telephone survey requires a balance between precision and loss of information to non-response. It is now standard survey practice to ask for income by category to minimise non-response, as the loss of precision is not considered to have any substantive impact on estimates. We did not ignore information; it was simply unavailable.

We acknowledge that using categorical instead of continuous individual household income information may have hindered our ability to rule out completely the residual confounding effect of individual household income on health. This, though, is unlikely to have affected our results.

Milyo expresses concerns about our having collapsed the top two income categories and included cases for which income data were missing, suggesting again that we ignored these issues. Although we did not clarify this in the paper, we included the observations of people who refused to answer the income question to avoid losing the information that this group could contribute to the estimates of the odds ratios for the demographic, risk factor, and household composition control variables. The relation between self reported health and household income flattened out after $\$ 35000$, and for ease of interpretation we combined the $\$ 35000$ to $<\$ 50$ and $\geqslant \$ 50000$ income categories as they did not differ substantively. We made these decisions after checking whether dropping people with missing income and combining the top two income categories affected the results; they did not.

A final concern of Milyo is that use of the Gini coefficient as a categorical rather than a continuous variable ignores important information. After determining that the loss of information made little difference to our conclusion we presented our findings in terms of Gini categories rather than in terms of a continuous Gini measure to make the results understandable to a broad audience. For most readers, the change in an odds ratio associated with a 1 unit change in the Gini coefficient has no intuitive meaning.

We do not see a need to qualify our original conclusion. The relation between income inequality and self reported health is robust. Even after we controlled for factors such as individual household income (though not as perfectly measured as might be), race, smoking, obesity, and educationall of which may be in the causal pathway between inequality and poor health-the relation remained significant.

Bruce P Kennedy Deputy director

Ichiro Kawachi Associate professor

Roberta Glass Research specialist

Deborah Prothrow-Stith Professor

Harvard School of Public Health, Boston,

MA 02115, USA

\section{Prediction of cardiovascular risk}

\section{Program is not suitable for diabetic patients}

EDITOR-Hingorani and Vallance describe a clinic based computer program for the management of cardiovascular risk factors. However, the program has limitations for diabetic patients.

This program and previous methods, together with the recent joint British recommendations, ${ }^{2}$ are based on algorithms derived from the Framingham heart study of 5573 people aged 30-74 years originally screened in 1968. However, only 4\% (237 subjects) of this cohort had diabetes, as defined by a random glucose concentration $>9 \mathrm{mmol} / \mathrm{l}$ or the use of diabetic treatment Importantly, diabetes was not classified according to type, and the presence of proteinuria or microalbuminuria (important cardiovascular risk factors in diabetes) were not included.

The prevalence and characteristics of other risk factors further highlight that people with diabetes are not average patients "diabetic dyslipidaemia," increased prevalence of hypertension, and ethnic origin (for example, south Asian) contribute to an increased atherogenic potential. Despite the strong link between triglyceride concentration and coronary heart disease in diabetes, this important risk factor was omitted from the program.

The glycaemic state was included in the program as a risk factor both as "diabetes" and as a blood glucose concentration. The impact of glycaemia on cardiovascular events is not dichotomous, but, like blood pressure, has a continuous relation. ${ }^{4}$ The inclusion of blood glucose as a variable is an important addition to risk assessment.

The present program and other methods derived from Framingham data have inconsistencies for the primary prevention of cardiovascular disease in diabetes. This is especially true for patients with type 2 diabetes, who have a 2 to 5 -fold increase in age adjusted mortality from cardiovascular disease. The emerging evidence is that patients with diabetes should be treated as recommended for secondary prevention. ${ }^{5}$

Andrew Zambanini Senior registrar in clinical pharmacology

Martin R Smith Specialist registrar in diabetes and endocrinology

Michael D Feher Senior lecturer in clinical

pharmacology

Section of Clinical Pharmacology, Imperial College School of Medicine and Beta Cell Diabetes Centre, Chelsea and Westminster Hospital, London

SW10 9NH

rnkk003@cxwms.ac.uk

1 Hingorani A, Vallance P. A simple computer program for guiding management of cardiovascular risk factors and prescribing. BMJ 1998:318:101-5. (9 January)

2 Wood D, Durrington P, Poulter N, McInnes G, Rees A Wray R Joint Briton P, Poulter N, Mchnes G, Rees A, Wray R.J Dint Brish recommendations on prevention of (suppl 2): S4-5.

3 Feher MD, Elkeles RS. Lipid modification and coronary heart disease in type 2 diabetes: different from the general population? Heart 1999;81:10-1.

4 Gerstein HC, Yusuf S. Dysglycaemia and risk of cardiovascular disease. Lancet 1996;347:949-50.

5 Haffner SM, Lehto S, Ronnemaa T, Pyorala K, Markku L. Mortality from coronary heart disease in subjects with type 2 diabetes and in nondiabetic subjects with and without prior myocardial infarction. $N$ Engl J Med 1998;339: 229-34.

\section{Hypothesis of program is flawed}

EDITOR-Hingorani and Vallance advocate using a computer program to predict the cardiovascular risk of individuals and estimate the benefit expected from treatment. ${ }^{1}$ They assume that the risk ratio corresponding to a decrease of a risk factor in a given individual is the same as the risk ratio between two people with the same difference in risk factors. We call this assumption the isotropy hypothesis. ${ }^{2}$ The isotropy hypothesis is unlikely to be true for several reasons. Firstly, for a given individual, the reduction in risk will not be proportional to the reduction in blood pressure for the range of blood pressures that treatment could produce. In other words, we do not believe that a person with an initial systolic blood pressure of $170 \mathrm{~mm} \mathrm{Hg}$ would obtain a relative risk reduction of stroke of about $50 \%$ if his blood pressure reached $155 \mathrm{~mm}$ $\mathrm{Hg}$ with treatment, about $75 \%$ if it fell to 140 $\mathrm{mm} \mathrm{Hg}$, and $88 \%$ if it fell to $115 \mathrm{~mm} \mathrm{Hg}$. Secondly, for coronary events, randomised controlled trials have reported differences between relative risks observed and expected from a same blood pressure reduction, ${ }^{3}$ which raises doubts about isotropy. Thirdly, a recent trial showed that using drugs to reduce blood pressure further than with conventional treatment has no effect on cardiovascular risk. ${ }^{4}$ We believe this approach may be dangerous and misleading. For example, it is simple to show a smoker what his risk would have been if he did not smoke However, this lower risk may not be the value he would achieve by giving up smoking, and is certainly not what a doctor can expect, on average, from interventions against smoking.

Hingorani and Vallance's proposal to determine patients' targets for blood pressure or cholesterol concentration based on 
the desired risk reduction may lead to unrealistic expectations and in some cases dangerous behaviour by prescribers or patients.

We favour the approach proposed by Jackson. ${ }^{5}$ A patient's absolute risk reduction is derived by multiplying the predicted risk by the relative risk reduction estimated from a systematic overview. This estimate of relative risk reduction could be modulated according to the results of a search for modifiers of treatment effect, ideally performed on an individual patient database from all available clinical trials. Such modifiers may include the intensity of reduction of the risk factor.

François Gueyffier Research fellow

Jean-Pierre Boissel Head

Clinical Pharmacology Unit, EA 643,

Claude Bernard University, BP 3041, 69394 Lyons

Cedex 03, France

1 Hingorani A, Vallance P. A simple computer program for guiding management of cardiovascular risk factors and guiding management of cardiovascular risk
prescribing. BMJ 1998:318:101-5. (9 January.)

2 Boissel JP, Guevffier F. Is the isotropy hypothesis true in hypertension? Findings from the INDANA data base. Controlled Clin Trials 1998;19(suppl 3S):85-6S.

3 Colins R, Peto R, MacMahon SW, Herbert P, Fiebach N, Eberlein K, et al. Blood pressure, stroke, and coronary heart disease. 2. Lancet 1990;335:827-38.

4 Hansson I, Zanchetti A, Carruthers SG, Dahlöf B, Elmfeldt $\mathrm{D}$, Julius S, et al. Effects of intensive blood pressure lowering and low dose aspirin in patients with hypertension: principal results of the hypertension optimal treatment (HOT) randomised trial. Lancet 1998;351:1755-62.

5 Jackson R, Barham P, Bills J, Birch T, McLennon L, MacMahon S, et al. The management of raised blood pressure in New Zealand. BMJ 1993;307:107-10.

\section{Authors' reply}

EDITOR-Any program designed to calculate cardiovascular risk is inevitably limited by the original data gathering process used to derive the risk equations. Despite Zambanini et al's concerns about the limited number of diabetic patients included in the original Framingham cohort, the Framingham risk equation is proving to be a robust tool for estimating risk in the United Kingdom. ${ }^{1}$ One advantage of a computer based approach is that as new risk factors are identified and estimates of risk further refined, the appropriate changes can be included in the predictions. We hope that further data on both diabetic and non-diabetic patients will be included in the program as they become available. All risk calculations on patients stored in the database will then be refined automatically.

We also considered it important to design a system which not only provided an assessment of risk but also indicated the likely maximum benefits of intervention. Gueyffier and Boissel raise doubts about the validity of such calculations, but our comparison of computer predictions with data from the West of Scotland coronary prevention study and recently published meta-analyses ${ }^{2}$ support the view that, for cholesterol lowering at least, individuals adopt a new level of risk predicted from the Framingham cohort study. As we explain in our paper, this is also likely to be true for stopping smoking, although the effects of blood pressure reduction on risk of coronary heart disease may be overestimated. Gueyffier and Boissel's proposal that the benefits of risk factor intervention be estimated from a systematic overview of intervention trials is a reasonable alternative, and our program could be adapted to perform such a task. Either way, the predictions for blood pressure intervention would be tested against trial data.

In designing this program, our aim was to take forward theoretical discussions about multiple risk factors, risk calculations, and the implementation of thresholds for statin and antihypertensive treatment. In particular, we felt there was a need to develop a too which would aid the practising doctor and "operationalise" the extensive available evidence on risk factors and intervention. ${ }^{3}$ The level of interest which our paper has generated, particularly inquiries about the availability of the program, seems to endorse our view that there is a great clinical need for a program such as ours.

Aroon D Hingorani British Heart Foundation intermediate fellow

Patrick Vallance Professor

Centre for Clinical Pharmacology, Department of

Medicine, University College London, Rayne

Institute, London WC1E 6]J

1 Haq IU, Ramsay LE, Yeo WW, Jackson PR, Wallis EJ. Is the Framingham risk function valid for Northern European populations? A comparison of methods for estimating $40-6$

2 Gould AL, Rossouw JE, Santanello NC, Heyse JF, Furber

CD. Cholesterol reduction yields clinical benefit. Impact of tatin trials. Circulation 1998:97.946-59.

3 Grover S. Gambling with cardiovascular risk: picking the winners and the losers. Lancet 1999;353:254-5.

\section{Secondary prevention in coronary heart disease}

\section{Effects of statins have been in addition to} those of aspirin and $\beta$ blockers

EDIToR-Ferner acknowledges the apparent similarity between the abilities of continuing aspirin and simvastatin to prevent "bad things." ${ }^{\prime} \mathrm{He}$ overlooks the fact that the positive outcomes of the secondary prevention statin studies were additional to the use of both aspirin and $\beta$ blockers according to the investigators' cardiological practices at the time (table)..$^{2-4}$ Since the inception of the Scandinavian simvastatin survival study over a decade ago, subsequent trials have tested lipid modification with statins against a background of increasingly optimal practice, comfortably exceeding that described in the survey by Campbell et al.

Ferner's argument is focused on cost effectiveness. The cost implications of aspirin, however, are negligible-indeed, many patients buy it themselves. The cos effectiveness of statins in secondary preven-

Percentages of patients in each study who were taking aspirin or $\beta$ blockers

\begin{tabular}{lccc} 
& & \multicolumn{2}{c}{$\%$ taking: } \\
\cline { 3 - 4 } Study & Treatment & Aspirin & 解 Blockers \\
\hline 4S $^{2}$ & Simvastatin & 37 & 57 \\
\hline CARE $^{3}$ & Pravastatin & 83 & 40 \\
\hline LIPID $^{4}$ & Pravastatin & 82 & 47 \\
\hline Campbell et al $^{5}$ & & 63 & 32
\end{tabular}

tion is established, equates to that of other accepted healthcare interventions, and will improve further as patents expire.

The benefits of aspirin and $\beta$ blockers are beyond doubt, but Ferner's message serves to inhibit further the implementation of treatment with statins in secondary prevention and the potential for further reductions in mortality and morbidity. Surely it is better to offer patients requiring secondary prevention the complete range of lifestyle and therapeutic options and, for cost savings, to concentrate on areas of less substantiated prescribing.

Jonathan Morrell Committee member, health care section of British Hyperlipidaemia Association Fitznells Manor Surgery, Ewell, Surrey KT17 1TF

Competing interests: Dr Morrell has received fees from pharmaceutical companies marketing lipid lowering drugs for speaking at and organising educational meetings.

1 Ferner RF. Secondary prevention in coronary heart disease. BMJ 1998;317:1592. (5 December.)

2 Scandinavian Simvastatin Survival Study Group. Randomised trial of cholesterol lowering in 4444 patients with coronary heart disease: the Scandinavian simvastatin survival study (4S). Lancet 1994;344:1383-9.

3 Sacks FM, Pfeffer MA, Moye LA, Rouleau JL, Rutherford $\mathrm{JD}$, Col TC, ex a cholo

4 Long-term Intervention with Pravastatin in Ischaemic Disease (LIPID) Study Group. Prevention of cardiovascular events and death with pravastatin in patients with coronary heart disease and a broad range of initial cholesterol levels. N Engl J Med 1998;339:1349-57.

5 Campbell NC, Thain J, Deans HG, Ritchie LD, Rawles JM, Squair JL. Secondary prevention in coronary heart disease: baseline survey of provision in general practice. BMJ 1998;316:1430-4

\section{Author's reply}

EDITOR-The proportion of patients receiving aspirin in the trials to which Morrell refers is encouraging. Evidence from Campbell et al's study suggests that many more patients could benefit from aspirin than receive it. ${ }^{1}$ Even in the trials, few patients were treated with $\beta$ adrenoceptor antagonists, which are underused. ${ }^{2}$ An important secondary prevention study from Southampton, which quoted high rates of use of aspirin, did not provide information about $\beta$ blockers.

Chen et al highlighted the difference between America's "best hospitals" and the rest by examining the outcomes for nearly 150000 elderly patients who had had heart attacks. ${ }^{4}$ One patient in 25 admitted to the best hospitals survived who would have died in the other hospitals. The authors ascribed this to two straightforward facts: $15 \%$ more patients were given aspirin and over 25\% more patients were given $\beta$ blockers in the best hospitals.

Morrell rightly points out that the benefits of aspirin and statins may be additive. However, the benefits of statins, even in this high risk population, fall short of miraculous. In one study (the long term intervention with pravastatin in ischaemic disease study) the absolute benefit of pravastatin $40 \mathrm{mg}$ daily was to save 1.9 lives per 610 patient years of treatment. ${ }^{5}$ That is one life saved for every 320 patient years of treatment, at a direct drug cost of nearly 
$£ 180000$ - over 10 years’ pay for an average wage earner.

When all patients who might benefit are taking aspirin and $\beta$ blockers, which cost little, we can worry more about the expensive treatments, whose ability to reduce relative risk is heavily promoted but whose absolute benefit is quite small.

R E Ferner Director

West Midlands Centre for Adverse Drug Reaction Reporting, City Hospital, Birmingham B18 7QH r.e.ferner@bham.ac.uk

Competing interests: Dr Ferner advises Birmingham Health Authority on prescribing matters.

1 Campbell NC, Thain J, Deans HG, Ritchie LD, Rawles JM, Squair JL. Secondary prevention in coronary heart disease: baseline survey of provision in general practice disease: baseline surve

2 Gottlieb SS, McCarter RJ, Vogel RA. Effect of betablockade on mortality among high-risk and low-risk blockade on mortality among high-risk and low-risk patients after myoc

3 Jolly K, Bradley F, Sharp S, Smith H, Thompson S, Kinmonth A-L, et al. Randomised controlled trial of follow up care in general practice of patients with myocardial infarction and angina: final results of the Southampton hear integrated care project (SHIP). BMJ 1999;318:706-11. (13 March.)

4 Chen J, Radford MJ, Wang Y, Marciniak TA, Krumholz HM. Do "America's best hospitals" perform better for acute myocardial infarction? N Engl J Med 1999;340:286-92

5 Long-term Intervention with Pravastatin in Ischaemic Disease (LIPID) Study Group Prevention of cardiovascular events and death with pravastatin in patients with coronary heart disease and a broad range of initial cholester

NEngl J Med 1998;339:1349-57.

\section{Minimisation is much better than the randomised block design in certain cases}

EDITOR-In commenting on our editorial ${ }^{1}$ Ross suggests that the randomised block design is similar to minimisation but has even more power. ${ }^{2}$ We are unaware of any publication which shows that this is the case. He also states that these two methods have the same disadvantage - that assignment to a block becomes a major undertaking. In fact, minimisation does not have the problem of assignment to a block that the randomised block design has, and this is precisely why minimisation was invented.

In the context of clinical trials the randomised block design is referred to as stratified randomisation-for example, the men and women each have their own random allocation series; if stratified randomisation is feasible it is indeed an excellent method for obtaining balanced treatment groups. However, stratified allocation becomes unwieldy and eventually impossible as the number of relevant patient characteristics increases. Ross mentions age, sex, or number of pack years smoked as patient characteristics that could be used in stratified allocation, but he does not consider what would happen if one wished to balance the treatment assignment for all three of these characteristics.

Suppose we have three age groups and four groupings of pack years smoked, plus, of course, two sexes. This gives 24 strata, and the randomised block design would therefore have to have 24 separate random allocation series. This might just be manageable in a large trial, but many trials have considerably more than three patient characteristics that relate to prognosis. For example, Lee et al compared their patient groups at baseline on 14 "selected" dichotomised characteristics, which in combination give $2^{14}(=16384)$ strata. ${ }^{3}$ Minimisation could handle treatment allocation in such a situation with ease, but the randomised block design would be in some difficulty.

Tom Treasure Professor of cardiothoracic surgery St George's Hospital Medical School, London SW17 0QT

Kenneth D MacRae Medical statistician 5 Northcroft Terrace, London W13 9SP

1 Treasure T, MacRae KD. Minimisation: the platinum standard for trials? BMJ 1998;317:362-3.

2 Ross N. Randomised block design is more powerful than minimisation. BMJ 1999;318:263. (23 January.)

3 Lee KL, McNeer F, Starmer F, Harris PJ, Rosati RA. Clinical judgment and statistics: lessons from a simulated randomized trial in coronary artery disease. Circulatio 1980;61:508-15.

\section{Is there a clinical future for the general practitioner?}

Editor-At the recent "Clinical Futures" conference, and in the book, ${ }^{1}$ a subtheme emerged about the perceived redundancy of the general practitioner. Diagnosis would be genotypic rather than phenotypic, treatment in the primary care setting would mostly be given by nurses or paramedics, and anything complicated would require secondary care, which could be accessed directly.

It is already clear that a large proportion of current general practitioners' workload could be carried out by nurses (but this is nothing new-Tudor Hart pointed it out in $\left.1985^{2}\right)$. Moreover the "corner shop" mentality of general practitioners, their central role in the primary healthcare team, and their status as employers (and often owners of the premises) is anachronistic and unsustainable. So the 1972 model, Future General Practitioner, ${ }^{3}$ has reached its sell-by date, and we must design a "new model." New model general practitioners will be employees of locality sized primary care trusts, and there will be fewer of them. Branch surgeries (which often will be located in shopping centres) will be staffed entirely by staff such as nurse practitioners, with networked, district-wide electronic records and telemedicine links to provide medical back up and access for patients.

It is unrealistic, however, to suppose that patients will no longer require persona advice from a doctor in primary care. On the contrary, the exponential growth of information and technical capability will need expert management to ensure minimisation of harm to, and maximisation of clinical effectiveness for, individual patients. General practitioners will have a key role in helping patients to make complex decisions about diagnosis and treatment. They will still need well developed consultation and other clinical skills, but in addition they must be experts in evidence based medicine and information technology. Thus they will be able to help patients to identify and prioritise their problems; ask structured, answerable questions based on those problems; search for, find, and appraise information to answer these questions; and discuss the findings and implications in a meaningful and useful way with patients. They will also need to be trained as educators and managers, in order to maximise the clinical and organisational effectiveness of their teams.

These skills are neither trivial nor dispensable. Far from becoming redundant, general practitioners, as highly skilled medical generalists and information specialists, will be perhaps the only essential doctors in the whole of healthcare practice. Everything else will be done by nurses, technicians, and robots.

Toby Lipman General practitioner and Northern and Yorkshire research training fellow

Westerhope Medical Group, Westerhope, Newcastle upon Tyne NE5 2LH

toby@tobylipm.demon.co.uk

1 Marinker M, Peckham M, eds. Clinical futures. London: BMJ Books, 1998

2 Hart JT. The world turned upside down: proposals for community-based undergraduate medical training (George Swift Lecture 1985). J R Coll Gen Pract 1985;35: 63-8

3 Roval College of General Practitioners. The future general practitioner:learning and teaching. London: RCGP, 1972.

\section{Role of general practitioners in NHS must not be undervalued}

\section{Author underestimated figures}

EDITOR-We should be grateful to Majeed for his re-estimation of the proportion of medical care that takes place in general practice. ${ }^{1}$ His calculation that the proportion is about $70 \%$ is, however, too low, as he has extracted the wrong figure from the fourth national survey of morbidity statistics from general practice. The stated figure of 2.9 consultations per person year is the doctor contact rate. The calculated consultation rate, which allows for the fact that there may be consultations for a range of separate conditions during the same visit, was 3.5 per person year, or 3.6 per person year allowing for underrecording in the national survey. ${ }^{2}$

For an annual estimate we must start with the total English population in 1991 minus prisoners and service personnel-48 million. This should be inflated by $3.5 \%$ for duplicate registrations (in the fourth national survey of morbidity in general practice) and then multiplied by 3.6 to give a projection of the total number of face to face consultations; this can be further increased by $8 \%$ to allow for telephone consultations. ${ }^{3}$ The resulting total is 193 million, or $76 \%$ of NHS medical care.

A better comparison would be to look at estimates of complete episodes of care. Here the estimated general practice rate from the fourth national survey of morbidity in general practice was 2.0 per person year"New and first ever episodes." Adjusted as before, this projects 111 million general practice episodes, compared with a hospital estimated total for 1991-2 of 23.5 million- 
3.5 million emergency inpatients, ${ }^{4} 11$ million first attenders at accident and emergency, ${ }^{5}$ and 9 million referral outpatient attendances. ${ }^{5}$ This suggests that the proportion of medical episodes that take place in general practice may be close to $83 \%$, which I believe corresponds to Chisholm's reference to " $90 \%$ of all episodes of health care" which Majeed mentions in the first paragraph of his letter.

Tom Hennell Strategic analyst

NHS Executive North West, Warrington WA3 7QN thennell@doh.gov.uk

1 Majeed A. Role of hospitals in NHS must not be undervalued. $B M J$ 1998:317:1653. (12 December)

2 Royal College of General Practitioners, Office of Population Censuses and Surveys, Department of Health. Morbidity statistics from general practice: fourth national stud, 1991-92. London: HMSO, 1995.

3 Office of Population Census and Surveys. General household survey 1991.London: HMSO, 1993.

Department of Health. Hospital episode statistics 1991-92 London: $\mathrm{DoH}, 1994$.

5 Department of Health. Outpatients and ward attenders for England 1991-92.London: DoH, 1993.

\section{Author's reply}

EDITOR-Hennell tries to shed more light on the proportion of episodes of medical care that take place in primary care. I think, however, that his statement that $76-83 \%$ of medical contacts take place in primary care is based on several invalid assumptions and consequently is incorrect.

Firstly, although it is true that patients often present to general practitioners with more than one problem at a time, the same is also true of patients presenting to hospital doctors. Secondly, it is inappropriate to include telephone consultations in the total for general practice contacts without also including them in the total for hospital contacts. Finally, in his calculation of completed episodes of care Hennell assumes that patients attending for repeat outpatient appointments do not present with new problems or with exacerbations of old problems. This assumption is also incorrect.

Until proved otherwise, the most accurate figure for the proportion of total medical contacts taking place in primary care remains the $70 \%$ quoted in my previous letter.

Azeem Majeed Senior lecturer in general practice School of Public Policy, University College London, London WC1H 9EZ

a.majeed@ucl.ac.uk

\section{Noise trauma after inflation of air bags in low speed car crashes}

\section{Article was unclear and possibly misleading}

EDITOR-Buckley et al draw attention to possible noise trauma and sensorineural hearing loss and tinnitus as a result of the inflation of air bags in low speed car crashes. ${ }^{1}$ Their report is unclear on several issues and may be misleading.

In neither of the two cases reported is mention made of how soon after the accident the audiometry was carried out. The accident in case 1 occurred in the United States, and audiometry was carried out in Leeds by one of the authors. There is no record of any hearing assessment in the United States, which is surprising given that the patient experienced bilateral hearing loss, tinnitus, and unsteadiness (the unsteadiness lasting two weeks). Patients' perception of hearing loss does not imply that such a loss was simply sensorineural; indeed, conductive loss may have occurred and been transient. The small high frequency hearing loss depicted on the left side in case 1 is not one that most patients will notice and may have been present before the accident. There is the added factor of a flight from the United States.

Sensorineural hearing loss has been reported after minor trauma to the ear'; it usually involves high frequencies and is transient. The hearing loss depicted in case 2 mainly involved low frequencies, and readers are not told if it was reversible. This patient had had high frequency hearing loss noted 18 months before the accident. It is unclear if the small additional loss in the high frequencies was in fact related to the trauma. This patient was receiving treatment for hyperlipidaemia and was 68 .

It would be useful to know if the associated tinnitus in both cases was bilateral and whether, with the undocumented improvement in hearing in the left ear in case 1, tinnitus on that side stopped.

S S M Hussain Consultant otologist

Directorate of Otolaryngology, Ninewells Hospital and Medical School, Dundee DD1 9SY

Musheerhussain@btinternet.com

1 Buckley G, Setchfield N, Frampton R. Two case reports of possible noise trauma after inflation of air bags in low possible noise tauma after is 18:499-500.(20 February.) Hed CSM Hea ing tym SsM. Heaning loss in the 4 to $8 \mathrm{kHz}$ range followng tympanic membrane perforation from minor trauma. Clin Otolaryngol 1995;20:211-2.

\section{Author's reply}

EDitor-In both cases audiometry was carried out more than three weeks after the injury; it was not carried out in the United States in case 1 . The suggestion of a transient conductive hearing loss is pure speculation and is largely irrelevant since the audiometrically measured loss is clearly sensorineural. The high frequency loss in the left ear may have been present before the accident, but this is also speculation. We disagree that it is a hearing loss that most patients would not notice. In a 38 year old patient it is significant and probably symptomatic. The damage to cochlear outer hair cells implied by such a loss affects frequency resolution and speech perception as well as simply volume of sound. Hussain's point about the flight from the United States being an added factor is a curious one. Flying may cause barotrauma to the middle ear with a temporary conductive hearing loss, but the loss here is sensorineural. Is he suggesting that it is due to flying?

Hussain's comments about case 2 repeat the points we discussed in the article. Deterioration due to age and other factors is always a possibility, but the deterioration seen is greater than would be likely in the time frame. Hussain also seems to miss the point in the article that the hearing loss occurred at both $1 \mathrm{kHz}$ and $4 \mathrm{kHz}$. Since the audiogram was obtained three weeks after the event the hearing loss is unlikely to be a transient effect. The "small" additional loss at high frequencies amounted to $25 \mathrm{~dB}$ at $3 \mathrm{kHz}$ and $4 \mathrm{kHz}$. We suspect that Hussain would not think this small if it affected him.

The initial tinnitus in the left ear in case 1 did indeed settle, but that in the right did not. The patient in case 2 had bilateral tinnitus, which was not present before the injury.

One final point should be made. Both subjects presented because they noticed a persistent hearing loss and tinnitus after inflation of the air bags. Other potential contributory factors always exist, but the evidence in the cases that we reported is compelling. The important issue is whether these cases are isolated occurrences or indicate a more widespread problem. Although the danger of overinterpretation always exists, we fail to see how the paper could be regarded as misleading.

Graham Buckley Consultant otolaryngologist Department of Otolaryngology (Head and Neck Surgery), St James's University Hospital, Leeds LS9 2TF

JGrahamBuckley@compuserve.com

\section{Every hospital must improve in-hospital resuscitation}

EDITOR-Timely and properly performed cardiopulmonary resuscitation and defibrillation save many lives. ${ }^{1}$ The first few moments and minutes are all-important.

Prehospital cardiac care is increasingly being used, and improvements must now be made to in-hospital cardiopulmonary resuscitation. Health care in hospitals is being increasingly compartmentalised, but provision of cardiopulmonary resuscitation should not be limited to a few individuals in any hospital. Various studies have shown the shortcomings of physicians. ${ }^{2}$ Now, Fielden and Bradbury show that surgeons and anaesthetists in theatre lack defibrillation skills. ${ }^{.}$

The resuscitation councils and the national health services should enforce a pragmatic policy to provide basic life support resuscitation in every area and advanced life support in some priority areas of our hospitals. Theatres and emergency rooms should be recruited into this process first. At least one person trained in advanced life support resuscitation should be available in every active operating theatre, and at all times in emergency rooms.

One possibility is to require surgeons, anaesthetists, and physicians working in operating theatres and emergency rooms to hold advanced life support certification before they can renew their medical licence. Only with such mandatory policies would hospitals be in a position to provide proper health care. No individuals or their families should be left to think that surgical 
procedures were carried out in less than ideal settings or that resuscitation was left to inadequately trained staff.

I presume that the will for this exists; let us find a way to restore and maintain the public's trust in our healthcare systems.

V M K Bhaskarabhatla Research associate, internal medicine associates

Mount Sinai Medical Center, New York, USA

Baskarbhat@aol.com

1 Advanced Life Support Working Party of the European Resuscitation Council. Guidelines for advanced life support. Resuscitation 1992;24:111-22.

2 Chin D, Morphet J, Coady E, Davidson C. Assessment of cardiopulmonary resuscitation in the membership examination of the Royal College of Physicians. I R Coll mation of the Royal College

3 Fielden JM, Bradbury NS. Observational study of defibrillation in theatre. $B M J$ 1999;318:232-3. (23 January.)

\section{Head lice can be controlled without application of insecticide lotions}

EDITOR-Dawes et al's evidence based case report about treatment for head lice was interesting as an exercise in evidence searching, but the authors failed to ask the right question in the first place. ${ }^{1}$ A more useful research question would have been, "In children attending primary care with head lice, what is the most effective intervention that will keep the problem under control?"

Head lice are most prevalent in primary school children, and the average number of adult lice per child is only $8-10 .^{2}$ This does not constitute a major health hazard, and there is little evidence of an association with impetigo as quoted in the article. Insecticide lotions are effective in killing head lice if used correctly, but what is the point of using repeated applications of chemicals on schoolchildren? The children may be cleared of head lice by insecticide lotion one day, only for them to be reinfected on their return to school the next day. Extensive and expensive campaigns in the past, with entire communities being treated with insecticide lotion, have shown that reinfection from outside sources occurs quickly.

Wet combing (combing through wet, well conditioned hair with a fine toothed nit comb), if done correctly and repeated every three days, will control the problem by physical removal of the lice. ${ }^{3}$ A plastic nit comb, a short teaching session with the Community Hygiene Concern's training video (160 Inderwick Rd, London N8 9JT), and support from health professionals will enable parents to take control of the problem of head lice in their children. In the long term, surely this is more effective and environmentally friendly than repeat prescribing of insecticide lotion.

Gill Lewendon Senior clinical medical officer South and West Devon Health Authority, Dartington TQ9 6JE

Gill.Lewendon@sw-devon-ha.swest.nhs.uk

1 Dawes M, Hicks NR, Fleminger M. Evidence based case report: Treatment for head lice. BMJ 1999:318:385-6. (6 February.)

2 Mellanby K. Natural population of the head louse on infected children in England. Parasitology 1940:34:180-4.

S Can purchasers adopt the innovations offered

by the voluntary sector? Kings Fund News 1994;17:8

\section{WHO should undertake full inquiry into Gulf war illness}

EDITOR-Coker et al found a high prevalence of various illnesses among British Gulf war veterans, confirming other recent reports from the United Kingdom and the United States. ${ }^{1}$ They say that they found no evidence for the existence of a unitary "Gulf war syndrome" and think that several possible causes are responsible for the symptoms reported. There have also been numerous reports of increasing ill health among Iraqi civilians, over and above deaths ascribed to malnutrition and lack of adequate medical care. These are widely blamed on the sanctions. ${ }^{2}$ Sikora describes both a breakdown in cancer services and a rising incidence of some cancers, ${ }^{3}$ and there are disturbing, if anecdotal, reports of an increase in major congenital malformations. ${ }^{4}$ Some possible causes (toxic chemicals from oil fires, chemical warfare agents, depleted uranium) could be common to both troops and Iraqis, but others (insecticides, multiple immunisations) could not; it is hard to blame cancer and congenital deformities on stress.

As Sikora notes," the World Health Organisation has already worked in Iraq, but to a limited extent. We propose that the WHO should be authorised-and supported-to undertake a full inquiry into both effects and causes of illness following the Gulf war, not least as we are told that this could be a foretaste of future high-intensity wars. In your accompanying editorial, ${ }^{5}$ Murphy writes that proactive prevention must be developed to reduce the burden of postwar illnesses. A comprehensive study such as we propose might go further and say that war as a way of settling disputes must be avoided until diplomacy as an alternative really has been ruled out. This was clearly not the case in 1990-1, nor, we believe, in the December 1998 bombing, in which hospitals seem to have been "collateral damage."

Robin Stott Chair

medact@gn.apc.org

Douglas Holdstock Secretary

Medact, London N19 4DJ

1 Coker WJ, Bhatt BM, Blatchley NF, Graham JT. Clinical findings for the first 1000 Gulf war veterans in the Ministry of Defence's medical assessment programme. BMJ 1999;318: 290-4. (30 January.)

2 Garfield R, Zaidi S, Lennock J. Medical care in Iraq after six years of sanctions. BMJ 1997;315:1474-5.

Sikora K. Cancer services are suffering in Iraq $B M J$ 1999;318:203. (16 January.)

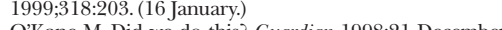
G2 1-4.

5 Murphy FM. Gulf war syndrome. BMJ 1999;318:274-5. (30 January.)

\section{GP surgeries were hard to contact over Christmas}

EdToR-Accident and emergency departments were overwhelmed with patients during the Christmas period. The health minister, Frank Dobson, believes that a flu epidemic precipitated this problem. A more likely explanation is that the general practice service in England and Wales broke down; people could not contact their general practitioners during the holiday period.
Number of attempts that had to be made to contact general practices by phone before and after Christmas

\begin{tabular}{lcc} 
& $\begin{array}{c}\text { Before } \\
\text { Christmas } \\
(\mathbf{n}=\mathbf{9 1})^{*}\end{array}$ & $\begin{array}{c}\text { After } \\
\text { Christmas } \\
(\mathbf{n}=\mathbf{9 3}) \dagger\end{array}$ \\
\hline Answered at 1st attempt & 20 & 54 \\
\hline Answered before or at 3rd attempt & 62 & 81 \\
\hline Answered before or at 6th attempt & 84 & 90 \\
\hline Answered before or at 9th attempt & 89 & \\
\hline
\end{tabular}

Surgeries were telephoned on Tuesdays and Thursdays between 0900 and 1130 or between 1300 and 1600 . ${ }^{*}$ Calls were made on 15, 17, and 22 Dec. Two practices could not be reached (three and six attempts made). tCalls were made on 29 Dec and 5, 7, and 12 Jan. Three practices could not be reached (three, four, and four attempts made).

As part of a pharmacological research project, I was involved with a telephone survey of general practitioners. We selected a simple random sample of general practitioners and hired a researcher to make phone calls to 200 of them. She attempted to contact 91 surgeries by phone before Christmas and 93 after Christmas. The table shows the number of times that she phoned each general practitioner's surgery before the phone was answered.

The results show that more phone calls had to be made to get through to a surgery before Christmas than after Christmas. It took up to nine attempts to get through to the 89 of 91 surgeries that were reached before Christmas, but after Christmas all calls to the 90 of 93 surgeries that were reached were answered within six attempts. These findings suggest that the general practice system in England responded poorly to patients' needs before Christmas, and patients would have had extreme difficulty in getting advice from a general practitioner. Many patients would probably therefore have attended a hospital casualty department.

The general practice system may have failed because the general practitioners on duty were overstretched because of a flu epidemic, adverse weather, or other reasons. A more likely explanation, however, is that the general practice service was understaffed over the Christmas period.

To prevent another fiasco it would be prudent for $\mathrm{Mr}$ Dobson to ensure that general practitioners keep their surgery doors open over the Christmas period. It makes little sense that, each year, even though a mid-winter hospital bed crisis is inevitable, general practitioners provide only a skeleton service at Christmas time. The effects of a failure of the general practice system cannot be immediately corrected and have a dramatic effect on the provision of beds, nurses, and medical staff for the rest of the year.

Andrew Rouse Senior lecturer

Department of Public Health, University of Birmingham, Birmingham BT15 2TT

\begin{tabular}{l} 
Rapid responses eBM] \\
$\begin{array}{l}\text { Rapid responses submitted directly to our } \\
\text { website are available on www.bmj.com }\end{array}$ \\
\hline
\end{tabular}

